\title{
Numerical Investigation of Damage Risks of Roadway Surrounding Rocks under Oblique Incident Dynamic Loads
}

\author{
Zhengyi Wang, ${ }^{1,2}$ Linming Dou,, ${ }^{1,2}$ Jing Li, ${ }^{1,2}$ Kai Kang, ${ }^{1,2}$ and Longfei Feng, \\ ${ }^{1}$ School of Mines, China University of Mining and Technology, Xuzhou 221116, China \\ ${ }^{2}$ Key Laboratory of Deep Coal Resource Mining, School of Mines, Ministry of Education of China, \\ China University of Mining and Technology, Xuzhou 221116, China \\ Correspondence should be addressed to Linming Dou; lmdou@126.com
}

Received 7 November 2016; Revised 3 January 2017; Accepted 29 January 2017; Published 8 March 2017

Academic Editor: Carlo Rainieri

Copyright (C) 2017 Zhengyi Wang et al. This is an open access article distributed under the Creative Commons Attribution License, which permits unrestricted use, distribution, and reproduction in any medium, provided the original work is properly cited.

\begin{abstract}
In order to quantitatively demonstrate the damage risks of roadway surrounding rocks and meanwhile comprehensively consider stress states of surrounding rocks, an index to evaluate damage hazards was established based on Mohr-Coulomb strength criterion. Taking the track roadway of Longwall Panel 402103 in Hujiahe Coal Mine as an example, damage risks and dynamic response characteristics of surrounding rocks under oblique incident dynamic loads were studied in accordance with the new evaluation criterion. The results show that all conventional analysis indexes only reflect the stress distribution characteristics of coal-rocks from a certain aspect in two-dimension space, while all stress components can be considered by the damage risk index, with the evaluation criterion quantified, which can comprehensively reveal the stress states and damage of coal-rock masses. Under dynamic loading, the overall damage risks and damage degrees of roadway surrounding rocks are attributed to the superposition results of dynamic and static loads. The dynamic loads not only aggravate the damage of shallow surrounding rocks but also increase the damage risks of deep parts. The engineering practice demonstrates that the analysis results coincide with in situ damage of roadway surrounding rocks.
\end{abstract}

\section{Introduction}

Rockburst is one of the typical dynamic hazards in coal mining, which extremely affects safety and production of mines [1]. Since the first recorded rockburst happened in England in 1738, the main mining countries like Germany, South Africa, Polish, Czech, Canada, Japan, France, and about more than 20 countries reported rockburst happening. Many researchers have studied rockburst from various aspects around the world [2-6]. It is found that about $85 \%$ of rockbursts occur in roadways due to the disturbances of external hypocenters, and dynamic damage of roadway surrounding rocks appears under the superposition of dynamic and static loads [7-12].

Currently, extensive researches have been carried out to study rockburst damage of roadway surrounding rocks under dynamic loads. In the aspect of theoretical research, the stress criterion and energy principle for the destruction of support structure of surrounding rocks under combined effects of static load and dynamic load were deduced [13]. Moreover, a rockburst prevention mechanism of synergizing pressure relief and reinforcement of surrounding rocks was proposed, where pressure releasing area in surrounding rock masses and reinforcing rock mass of sufficient thickness were set in surrounding rock [14]. Furthermore, it was proved that the total stress of the bolt on the side facing the stress wave was the superposition of static axial stress, dynamic stress of bolt vibration, and subsidiary stress caused by the surrounding rock deformation under dynamic load [15]. Correspondingly, in terms of numerical methods, the whole process of roadway rockburst failure and the attenuation properties of shock wave were investigated by using UDEC discrete element numerical simulation software [16]. In addition, the dynamic response laws of anchor bolts under explosive loads were studied by using LS-DYNA numerical simulation software, which indicated that anchor bolts placed in different positions around the roadway exhibited significantly different stress characteristics [17]. 
However, existing researches analyze the response and damage characteristics of roadway surrounding rocks under dynamic loads only either from the stress and displacement of surrounding rocks in a certain direction or from energy. However, owing to the stress and displacement in a single direction being unable to comprehensively reflect stress states of surrounding rocks, these researches fail to reveal the real damage of surrounding rocks. Although stress states of surrounding rocks can be completely considered from the perspective of energy, the energy theory is still used as a criterion for rockburst and cannot quantitatively analyze the probability of damage occurring on surrounding rocks. Damage characteristics of roadway surrounding rocks under dynamic loads need to be studied based on the strength criteria of surrounding rocks. At present, Mohr-Coulomb strength criterion proposed by C. A. Coulomb in 1773 and later explained by Mohr using new theories is the most widely used strength criterion [18]. Although Mohr-Coulomb strength criterion is able to comprehensively consider all stress components of coal-rock unit bodies in a plane, similar to energy theory, it is merely used as a damage criterion but unable to accurately analyze the damage risk.

To quantify the damage risk of surrounding rocks and at the same time comprehensively consider stress states of roadway surrounding rocks, an index (damage risk index) to evaluate damage risk of roadway surrounding rocks was established based on Mohr-Coulomb strength criterion. In addition, the damage risks and dynamic response characteristics of roadway surrounding rocks under oblique incident dynamic loads were analyzed by taking the track roadway of Longwall Panel 402103 in Hujiahe Coal Mine as an example. A guidance for engineering practices is expected to be provided through these studies.

\section{Establishment of the Index for Evaluating Damage Risks of Coal-Rock Unit Bodies Based on Mohr-Coulomb Strength Criterion}

It is well known that Mohr-Coulomb strength criterion can be represented by the maximum principal stress $\sigma_{1}$ and the minimum principal stress $\sigma_{3}$ as [19]

$$
\sigma_{1}=\frac{1+\sin \phi}{1-\sin \phi} \sigma_{3}+\frac{2 c \cdot \cos \phi}{1-\sin \phi},
$$

where $c$ and $\phi$ represent the cohesion and the internal friction angle, respectively. As shown in Figure 1, straight lines $L_{1}$ and $L_{2}$ indicate the damage criterion determined by (1) and the safest principal stress state (namely, $\sigma_{1}=\sigma_{3}$ ), respectively. When point $P\left(\sigma_{3}, \sigma_{1}\right)$ is above the straight $L_{1}$, the principal stress state meets formula (2):

$$
\sigma_{1}>\frac{1+\sin \phi}{1-\sin \phi} \sigma_{3}+\frac{2 c \cdot \cos \phi}{1-\sin \phi} .
$$

Under this condition, the coal-rock's failure will occur and this coal-rock unit body belongs to damaged zones.

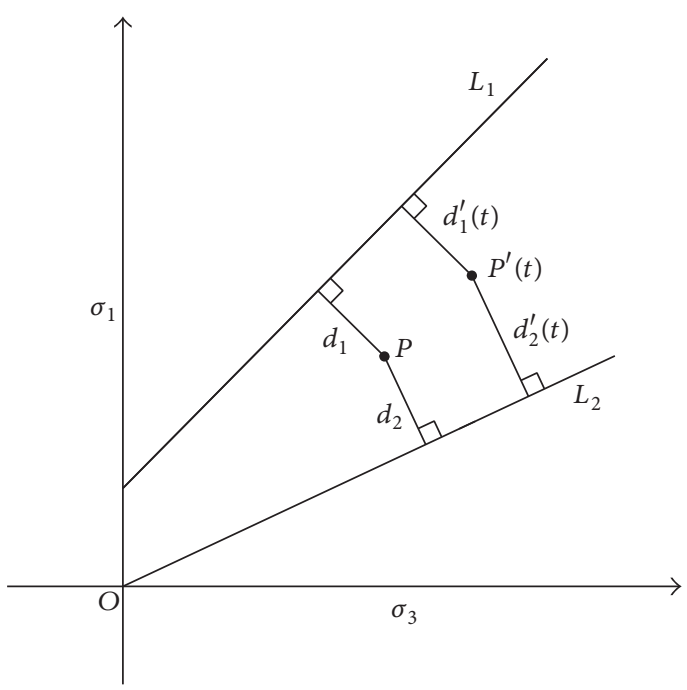

Figure 1: $\sigma_{1}-\sigma_{3}$ coordinate system.

However, principal stress states of all undamaged coalrock unit bodies are found in the zone between straight lines $L_{1}$ and $L_{2}$, which conform to formula (3):

$$
\sigma_{3} \leq \sigma_{1} \leq \frac{1+\sin \phi}{1-\sin \phi} \sigma_{3}+\frac{2 c \cdot \cos \phi}{1-\sin \phi}
$$

Accordingly, a new index (damage risk index $W$ ) to evaluate damage risks of coal-rock unit bodies can be defined as

$$
W=\frac{d_{2}}{d_{1}+d_{2}} \times 100 \%,
$$

where $d_{1}$ and $d_{2}$ demonstrate the distance of point $P\left(\sigma_{3}, \sigma_{1}\right)$ to straight lines $L_{1}$ and $L_{2}$, respectively, which can be described as

$$
\begin{aligned}
& d_{1} \\
& =\frac{\left|((1+\sin \phi) /(1-\sin \phi)) \sigma_{3}-\sigma_{1}+(2 c \cdot \cos \phi) /(1-\sin \phi)\right|}{\sqrt{((1+\sin \phi) /(1-\sin \phi))^{2}+1}}, \\
& d_{2}=\frac{\left|\sigma_{3}-\sigma_{1}\right|}{\sqrt{2}} .
\end{aligned}
$$

Specifically, point $P\left(\sigma_{3}, \sigma_{1}\right)$ is located on the straight line $L_{2}$ when $W=0$, which is known as the absolute safe state, while point $P\left(\sigma_{3}, \sigma_{1}\right)$ is located on the straight line $L_{1}$ when $W=100 \%$, which is called the critical damage state.

At present, the leveling forecasting method, which was proposed by Dou and He [20], has been widely used in coal mines with rockburst danger and has achieved stratifying achievements $[21,22]$. Thus the damage risk can be similarly further graded by referring to this forecasting method, as shown in Table 1.

In accordance with superposition theories [21, 23] of dynamic and static loads, the additional dynamic stress increments of the maximum principal stress $\sigma_{1}$ and the minimum principal stress $\sigma_{3}$ in a coal-rock unit body caused 
TABLE 1: Classifications of damage risks of rockburst.

\begin{tabular}{lcc}
\hline Damage risk degree & Damage risk state & Damage risk index \\
\hline A & No damage risk & $0-25 \%$ \\
B & Low damage risk & $25 \%-50 \%$ \\
C & Medium damage risk & $50 \%-75 \%$ \\
D & High damage risk & $75 \%-100 \%$ \\
\hline
\end{tabular}

by the dynamic load $\sigma_{\mathrm{d}}(t)$ changing with time can be defined as $\sigma_{1 \mathrm{~d}}(t)$ and $\sigma_{3 \mathrm{~d}}(t)$, respectively. Correspondingly, the dynamic variation of principal stresses and the overall principal stresses under the superposition of dynamic and static loads is represented as $P_{\mathrm{d}}\left(\sigma_{3 \mathrm{~d}}(t), \sigma_{1 \mathrm{~d}}(t)\right)$ and $P^{\prime}\left(\sigma_{3}+\right.$ $\left.\sigma_{3 \mathrm{~d}}(t), \sigma_{1}+\sigma_{1 \mathrm{~d}}(t)\right)$, respectively. Under the circumstances, the distances of the corresponding point $P^{\prime}$ to the straight lines $L_{1}$ and $L_{2}$ are changed into $d_{1}^{\prime}(t)$ and $d_{2}^{\prime}(t)$. Accordingly, the damage risk index of the coal-rock unit body under the superposition of dynamic and static loads is expressed by

$$
W^{\prime}(t)=\frac{d_{2}^{\prime}(t)}{d_{1}^{\prime}(t)+d_{2}^{\prime}(t)} \times 100 \%
$$

\section{Numerical Simulation of Damage Risks of Roadway Surrounding Rocks under Oblique Incident Dynamic Loads}

3.1. Establishment of Numerical Simulation Model. In order to obtain damage risk indexes of each zone and judge whether the failure occurs, the function get_ $W$, whose solving procedure is displayed in Figure 2, was programmed by using Fish language in $\mathrm{FLAC}^{2 \mathrm{D}}$, based on Mohr-Coulomb strength criterion and the definition of damage risk index. Loop statements were the subject of the function get_ $W$ for the purpose of traversing all zones of the model. The judgment and execution statements were designed according to the new evaluation criterion. Besides, $i_{\text {zones }}$ and $j_{\text {zones }}$ represent the number of zones in $x$-axis and $y$-axis direction, respectively. Since the focus of this paper is damage risks before failure instead of mechanical characteristics of damaged coal-rock unit bodies, zones bearing stresses larger than ultimate failure strengths are regarded as belonging to damaged zones in spite of their residual strengths and their ability of continuing bearing stresses.

Due to the fact that the damage risk index $W$ is not the built-in variable of zones in FLAC ${ }^{2 \mathrm{D}}$, an additional variable of zone needs to be configured before modeling [24]. Since Mohr-Coulomb model, which is known as the most commonly used model in FLAC ${ }^{2 \mathrm{D}}$, is the foundation of theories about the damage risk index, it was still applied as the constitutive model in the numerical analysis. Under this condition, distributions of damage risk indexes and damaged zones can be obtained after calling the function get_ $W$. Figure 3 displays the complete solving procedure of the numerical simulation.

Taking the geological conditions of Longwall Panel 402103 of Hujiahe Coal Mine in Binchang Coal Group, Shaanxi, China, as an example, the track roadway of Longwall
Panel 402103 was studied, based on the data gotten from in situ measurements and laboratory tests. The property parameters of the model are shown in Table 2 and the lateral pressure coefficient was 1.2. The model whose size was $40 \mathrm{~m}$ $\times 49 \mathrm{~m}$ in length and height contained $160 \times 178=28,480$ units. Interfaces were set between strata to simulate weak structural planes. The buried-depth and the size of the track roadway of Longwall Panel 402103 were $-500 \mathrm{~m}$ and $5.5 \mathrm{~m}$ (width) $\times 3.7 \mathrm{~m}$ (height), respectively. By using slicing fully mechanized top-coal caving mining process, the top slice (13 $\mathrm{m}$ in thickness) was firstly mined and the roadway was arranged along the coal seam floor of the top slice, while $10 \mathrm{~m}$ thick bottom coal was retained as the bottom slice of the coal seam. The anchor bolts in the roof and the two sidewalls of the roadway and anchor cables were simulated using cable elements according to the in situ supporting parameters (Figure 4). The pretightening forces of the roof anchor bolts, the anchor bolts in the sidewalls, and the anchor cables were $60 \mathrm{kN}, 40 \mathrm{kN}$, and $120 \mathrm{kN}$, respectively. In this study, the problem related to roadway surrounding rocks was regarded as a plane strain problem and the lower boundary of the model was fixed while $14.75 \mathrm{MPa}$ uniform load was acting on the upper boundary. Furthermore, trapezoidal compressive stresses were imposed to both sides and the displacement in $x$ direction was limited. The numerical simulation model is demonstrated in Figure 5.

The built-in dynamic module in FLAC $^{2 \mathrm{D}}$ was adopted for the dynamic analysis. The dynamic load source was applied in the coal seam above the roadway with a vertical distance of $7.5 \mathrm{~m}$ to the roadway roof and a horizontal distance of $13.75 \mathrm{~m}$ to the sidewall near the source to simulate the typical oblique-incidence dynamic disturbance during track roadway tunneling. Researches [25-27] show that the waveform of the dynamic disturbance source, which is caused by the in situ excavation blasting near the roadway and the roof weighting around working face, usually belongs to the single-peak waveform. Therefore, the waveform of dynamic load source can be simplified as a half-sine P-wave (Figure 6), and the corresponding time-history curve $P_{\mathrm{d}}(t)$ is expressed as

$$
P_{\mathrm{d}}(t)= \begin{cases}\frac{1}{2} P_{\mathrm{dm}}\left[1-\cos \left(\frac{2 \pi t}{t_{\mathrm{dm}}}\right)\right] & 0<t<t_{\mathrm{dm}} \\ 0 & t>t_{\mathrm{dm}}\end{cases}
$$

where $P_{\mathrm{dm}}$ and $t_{\mathrm{dm}}$ represent the amplitude and action time of dynamic loads, respectively. Taking the $10^{4} \mathrm{~J}$ energy level of microearthquake during the track roadway excavation in Panel 402103 as the study object, the relevant parameters can be approximately obtained (Table 3), based on the statistical results from in situ measurements and laboratory tests [28, 29].

Research [30] suggests that the calculation equation of $\mathrm{P}$ wave dynamic loads can be expressed as

$$
P_{\mathrm{dm}}=\rho_{\text {coal }} C_{\mathrm{P}} v_{\mathrm{pp}},
$$

where $\rho_{\text {coal }}, C_{\mathrm{P}}$, and $v_{\mathrm{pp}}$ demonstrate the density of coalrock, the propagation velocity of $P$-wave, and the maximum peak velocity of tremors, respectively. The amplitude $P_{\mathrm{dm}}$ of 


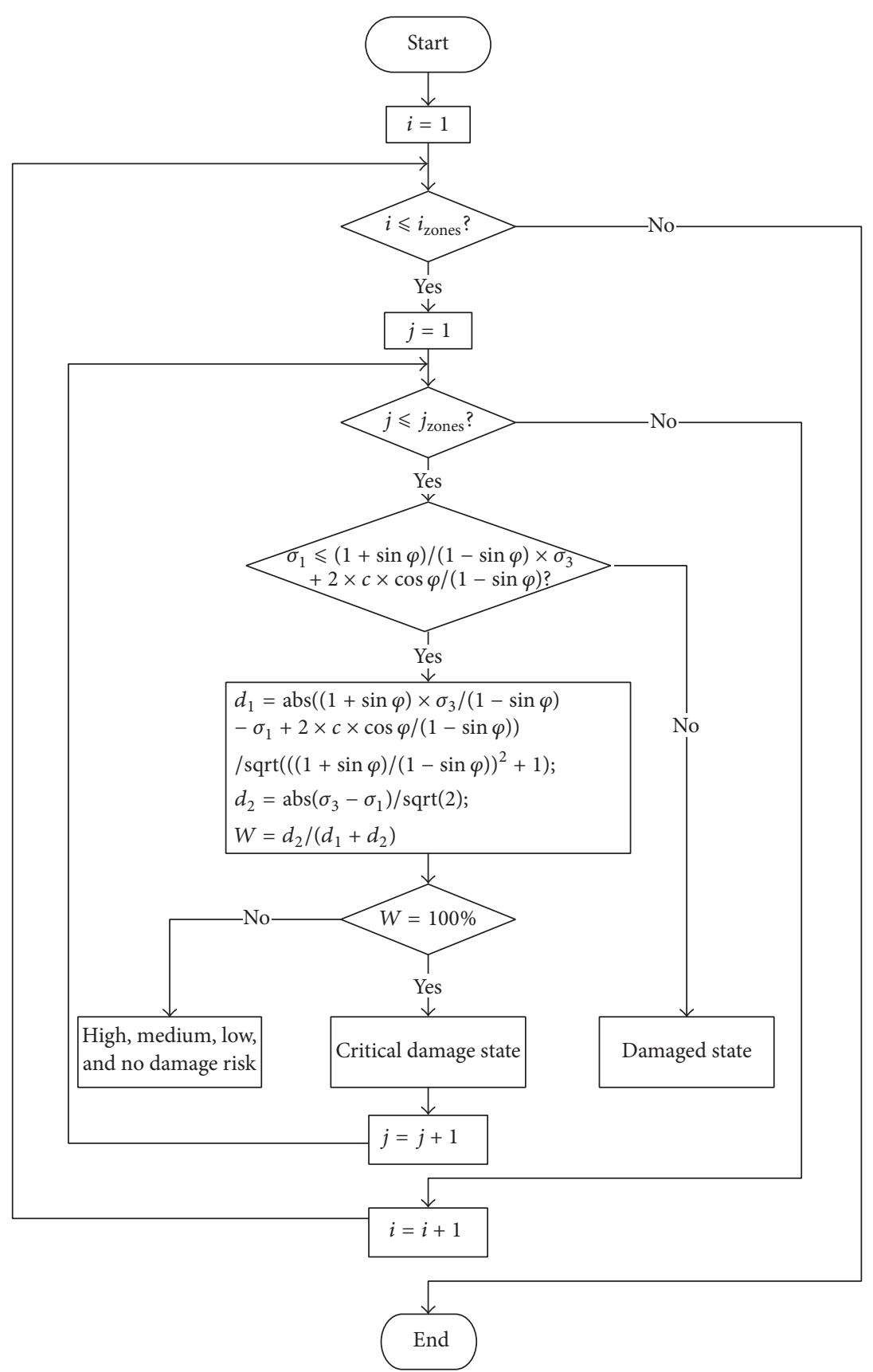

FIGURE 2: Flow chart for solving the damage risk indexes and distinguishing the damaged zones.

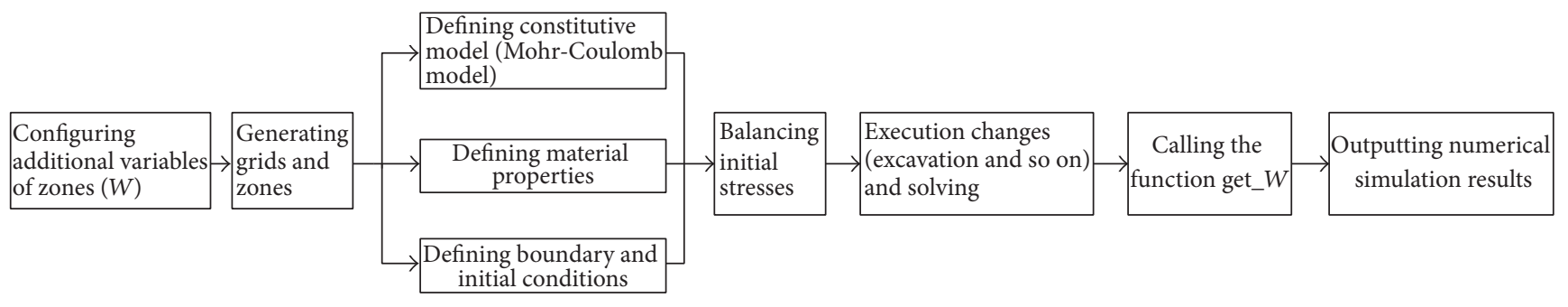

FIGURE 3: Solving procedure of the numerical simulation. 


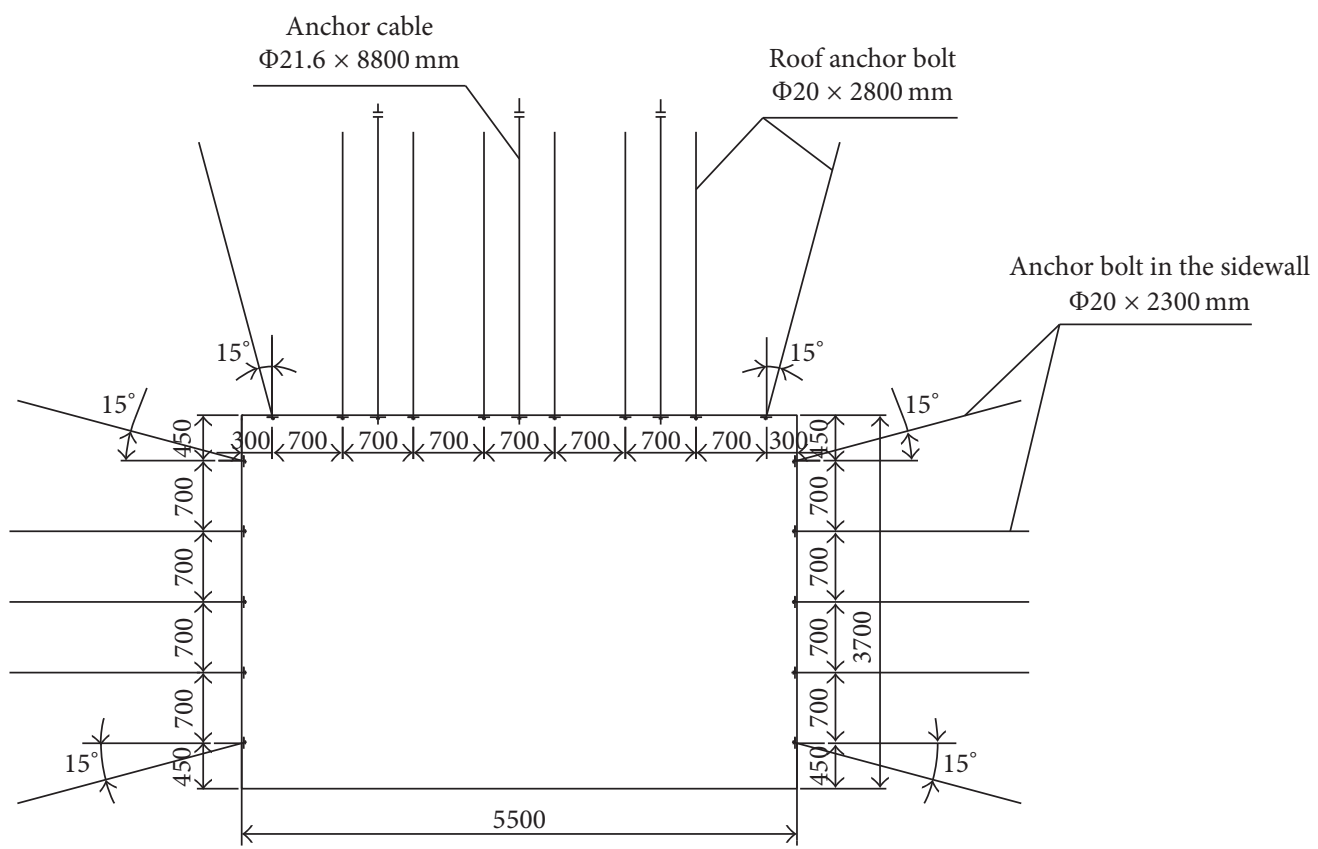

FIGURE 4: Supporting parameters of the track roadway in Longwall Panel 402103.

TABLE 2: Property parameters of numerical simulation model.

\begin{tabular}{lcccccc}
\hline Strata & Thickness $/ \mathrm{m}$ & Density $/\left(\mathrm{kg} \cdot \mathrm{m}^{-3}\right)$ & Bulk $/ \mathrm{GPa}$ & Shear/GPa & Cohesion $/ \mathrm{MPa}$ & Friction angle $/^{\circ}$ \\
\hline Main roof & 10 & 2508 & 9.34 & 6.25 & 4.5 & 39 \\
Immediate roof & 6 & 2348 & 2.21 & 2.10 & 2.6 & 38 \\
Coal & 23 & 1320 & 1.99 & 0.97 & 36 \\
Main floor & 10 & 2480 & 8.21 & 5.91 & 4.3 & 39 \\
\hline
\end{tabular}

TABLE 3: Relevant parameters of the calculation for P-wave dynamic loads.

\begin{tabular}{|c|c|c|c|c|}
\hline $\begin{array}{l}\text { Energy level of } \\
\text { microearthquake/J }\end{array}$ & $\begin{array}{c}\text { Maximum peak velocity of } \\
\text { tremors } /\left(\mathrm{m} \cdot \mathrm{s}^{-1}\right)\end{array}$ & Tremor frequency/Hz & $\begin{array}{c}\text { Propagation velocity of } \\
\text { P-wave } /\left(\mathrm{m} \cdot \mathrm{s}^{-1}\right)\end{array}$ & $\begin{array}{c}\text { Density of } \\
\text { coal } /\left(\mathrm{kg} \cdot \mathrm{m}^{-3}\right)\end{array}$ \\
\hline $10^{4}$ & 3.4 & 10 & 3350 & 1320 \\
\hline
\end{tabular}

the disturbance valued about $15 \mathrm{MPa}$ by substituting these above parameters in Table 3 into (8), and the action time $t_{\mathrm{dm}}$ can be calculated as $t_{\mathrm{dm}}=1 / f=0.1 \mathrm{~s}(f$, which represents the tremor frequency, equals $10 \mathrm{~Hz}$ ). In addition, the free field boundary is applied to eliminate the influence of boundaries on the stress wave propagation. Due to the fact that a fraction $D$ of critical damping for coal-rock falls into 2$5 \%$ [31], the corresponding local damping coefficient $\alpha_{\mathrm{L}}$ can be conservatively calculated as $\alpha_{\mathrm{L}}=\pi D=\pi \times 0.05 \approx 0.1571$.

Consequently, the damage risks of roadway surrounding rocks under static and oblique incident dynamic loads can be solved according to the solving procedure in Figure 3, based on actual parameters about the track roadway of Panel 402103.

3.2. Simulation Results and Analysis. Taking the regions within $0-10 \mathrm{~m}$ away from the roadway surfaces as the research area, three main research aspects will be analyzed in detail, which are as follows: (1) comparisons between the analysis index of damage risks and conventional analysis indexes; (2) comparisons of damage risks under the stable state after dynamic disturbances and static loads; (3) time-history responses of the analysis index of damage risks.

3.2.1. Comparisons between the Analysis Index of Damage Risks and Conventional Analysis Indexes. Taking stress states of roadway surrounding rocks under static loads as an example, distributions of damage risk grades and conventional analysis indexes under static loads are shown in Figure 7. It can be seen from Figures $7(a)-7(e)$ that the rest of conventional analysis indexes exhibit axially symmetrical distributions with the central line of the roadway except for the centrosymmetric distribution of the shear stresses $\tau_{x y}$ with the roadway center being the symmetry center. The horizontal stresses $\sigma_{x}$ in the roof and floor are obviously larger than those in both sidewalls, and conversely, the vertical stresses $\sigma_{y}$ in both sidewalls are significantly larger than those in the roof and floor. Besides, the maximal principal 


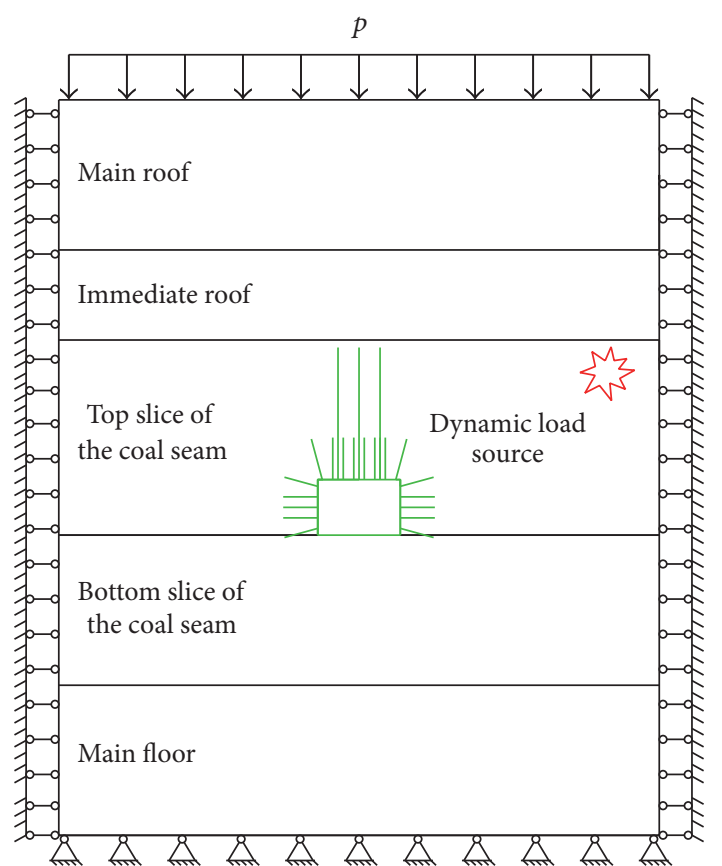

FIGURE 5: Numerical simulation model.

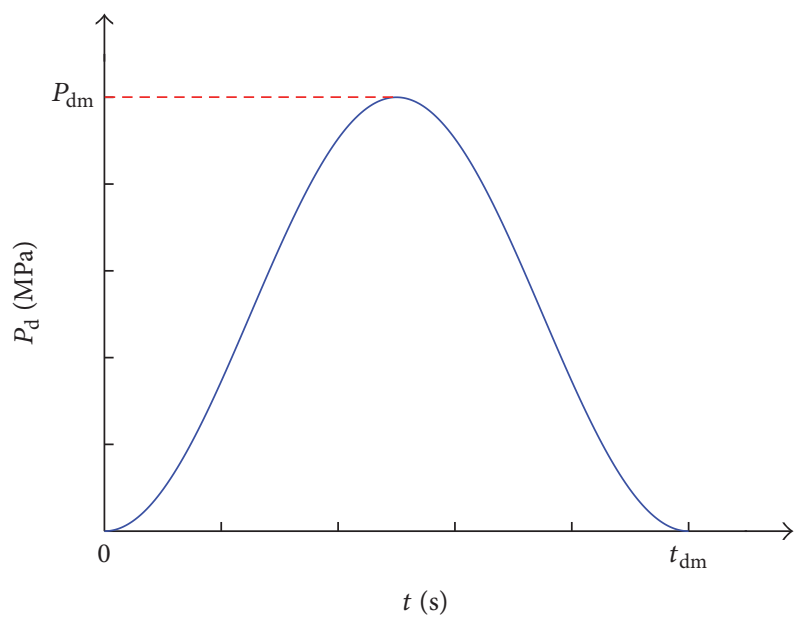

FIgure 6: The waveform of dynamic load $p_{\mathrm{d}}(t)$ with an amplitude of $p_{\mathrm{dm}}$ and action time of $t_{\mathrm{dm}}$.

stress $\sigma_{1}$ presents the unimodal distribution of increasing firstly and decreasing afterwards while the minimal principal stress $\sigma_{3}$ gradually increases from the roadway surface to deep surrounding rocks. However, all these analysis indexes only reflect the stress distribution characteristics of coalrocks from a certain aspect, while the comprehensive stress states are not taken into account, letting alone the quantitative analysis of damage risks according to them.

Figure 7(f) displays distributions of damage risk grades and damaged zones of roadway surrounding rocks. In this figure, zones at different damage risk grades similarly appear the axially symmetrical distribution with the center line of the roadway. Meanwhile, the regions closest to damaged zones present the highest damage risk state (namely, the critical damage state) and corresponding damage risk grades descend successively from high, medium, and low to no damage risk from the roadway surface to deep surrounding rocks. In addition, the damage risks in the roof and floor are higher than those in both sidewalls of the roadway. Thus the goal of comprehensively and quantitatively evaluating damage risks can be achieved by defining the damage risk indexes and grades, compared with conventional analysis indexes. Moreover, damage risks of undamaged zones are displayed in the same figure with distributions of damaged zones in this way, which shows a significant superiority.

\subsubsection{Comparisons of Damage Risks under the Stable State} after Dynamic Disturbances and Static Loads. Figure 8 shows the distributions of damage risk grades under the stable state after dynamic disturbances, which are attributed to the superposition results of dynamic and static loads. It can be seen that regions of each damage risk grade exhibit nonaxisymmetrical distributions with the central line of the roadway under oblique incident dynamic loads, compared with the axisymmetrical distributions of damage risk grades under static loads. That is to say, the damage risk levels of surrounding rocks near the source are higher than those remote from the source. Furthermore, overall damage risk levels of roadway surrounding rocks under the stable state after dynamic disturbances are significantly higher than those under static loads.

In order to quantitatively reveal the overall damage risk of surrounding rocks within a $10 \mathrm{~m}$ range away from the roadway surfaces, without damaged zones being considered, an index $\bar{W}$ of overall damage risk can be defined as

$$
\bar{W}=\frac{W_{1} \cdot a_{1}+W_{2} \cdot a_{2}+W_{3} \cdot a_{3}+W_{4} \cdot a_{4}+W_{5} \cdot a_{5}}{a_{1}+a_{2}+a_{3}+a_{4}+a_{5}},
$$

where $W_{1}$ represents the damage risk index corresponding to the critical damage state; namely, $W_{1}=100 \% . W_{2}-W_{5}$ indicate the medians of intervals of damage risk indexes at each risk grade from high to no damage risk states; namely, $W_{2}=$ $87.5 \%, W_{3}=62.5 \%, W_{4}=37.5 \%$, and $W_{5}=12.5 \%$. Moreover, $a_{1}-a_{5}$ demonstrate the distribution areas of each risk grade from the critical to no damage risk states. By substituting corresponding parameters in Figures 7(f) and 8 into (9), the overall damage risk indexes of roadway surrounding rocks under the stable state after dynamic disturbances and static loads are obtained (Figure 9).

It can be seen from Figures 7(f), 8, and 9 that the overall damage risks in the floor, roof, and two sidewalls of the roadway are in a decreasing order as $33.45 \%, 32.18 \%$, and $21.29 \%$, and meanwhile, the floor, roof, and two sidewalls show descending areas of damaged zones of $1.57 \mathrm{~m}^{2}, 0.73 \mathrm{~m}^{2}$, and $0.41 \mathrm{~m}^{2}$ under static loads. These indicate that as the horizontal stress fields are larger than the vertical stress fields under static loads, the damage degrees and overall damage risks in the roof and the floor are higher than those in two sidewalls. However, since the floor is not supported, the damage degree and overall damage risk in the floor are larger than those in the roof. 

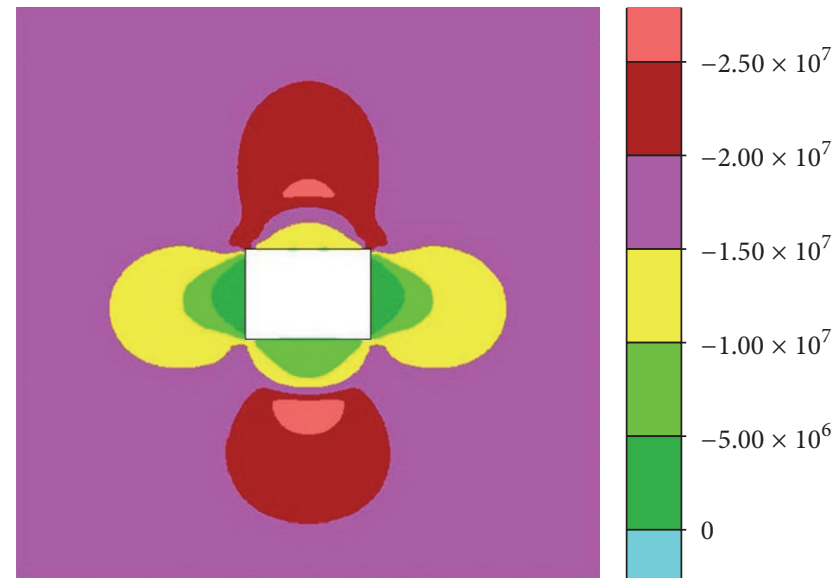

(a) Horizontal stress $\sigma_{x}$

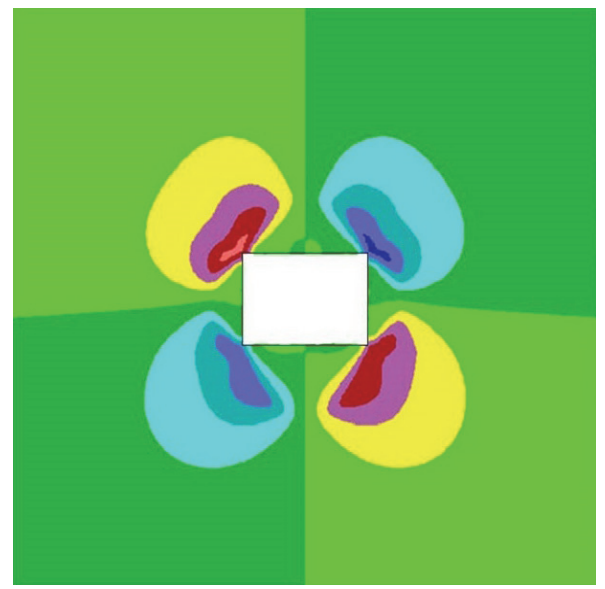

(c) Shear stress $\tau_{x y}$

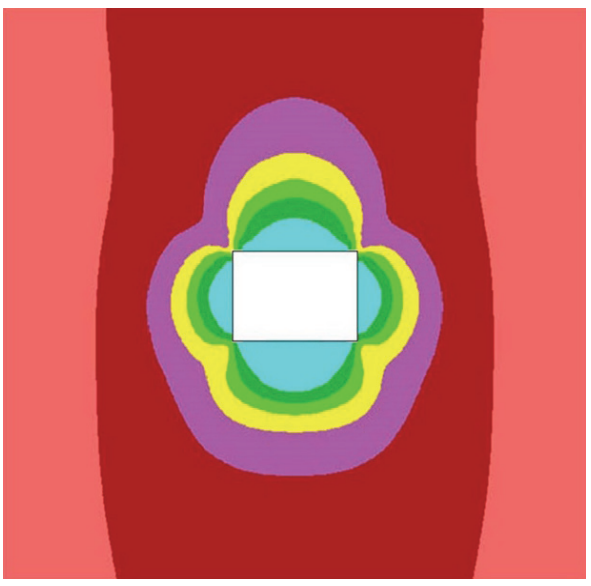

(e) Minimal principal stress $\sigma_{3}$
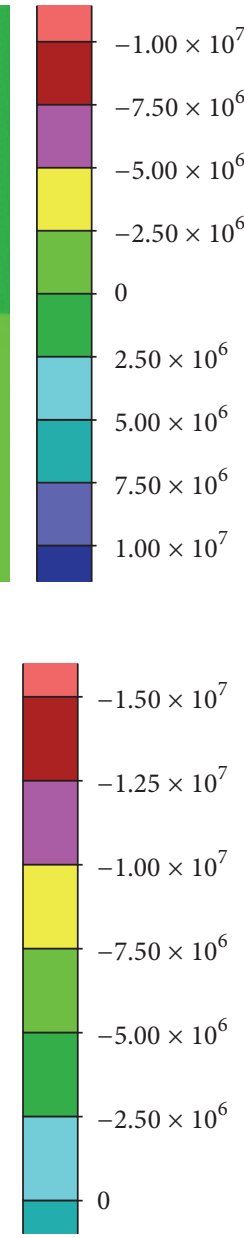
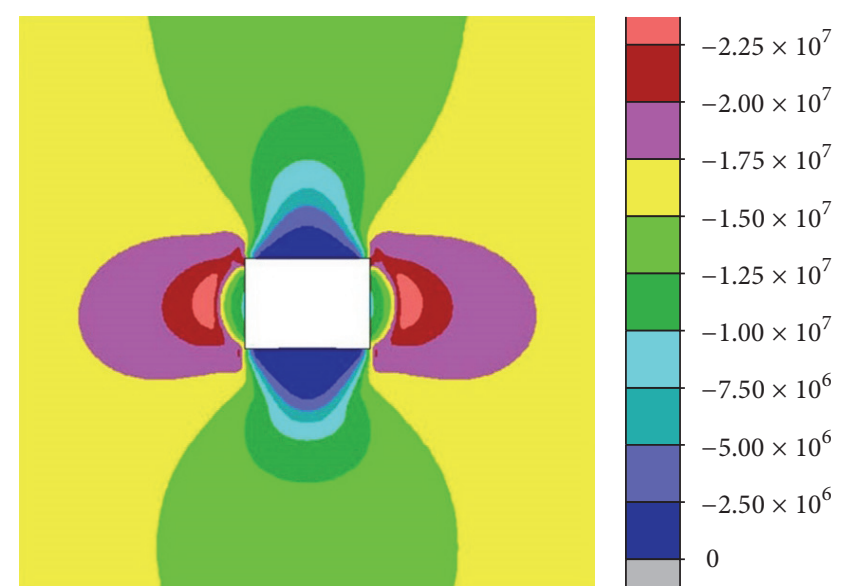

(b) Vertical stress $\sigma_{y}$
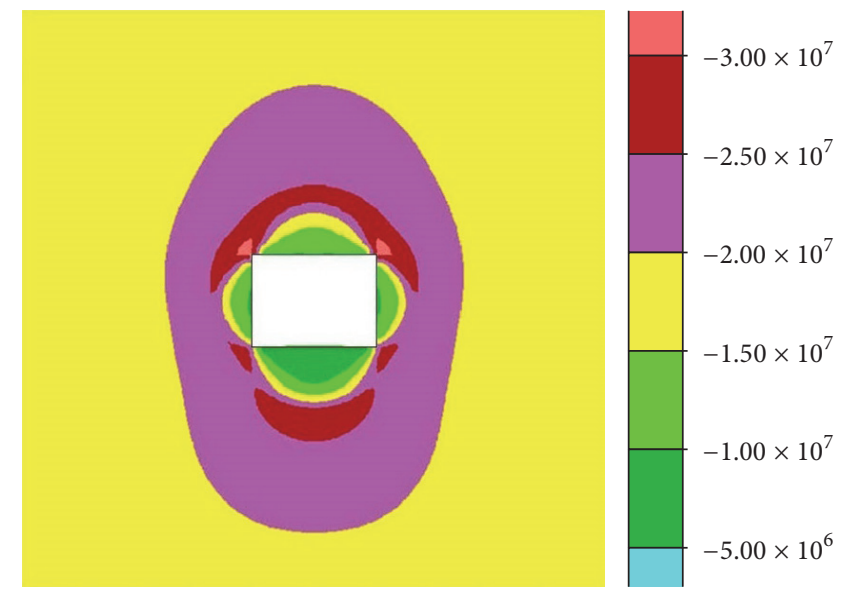

(d) Maximal principal stress $\sigma_{1}$
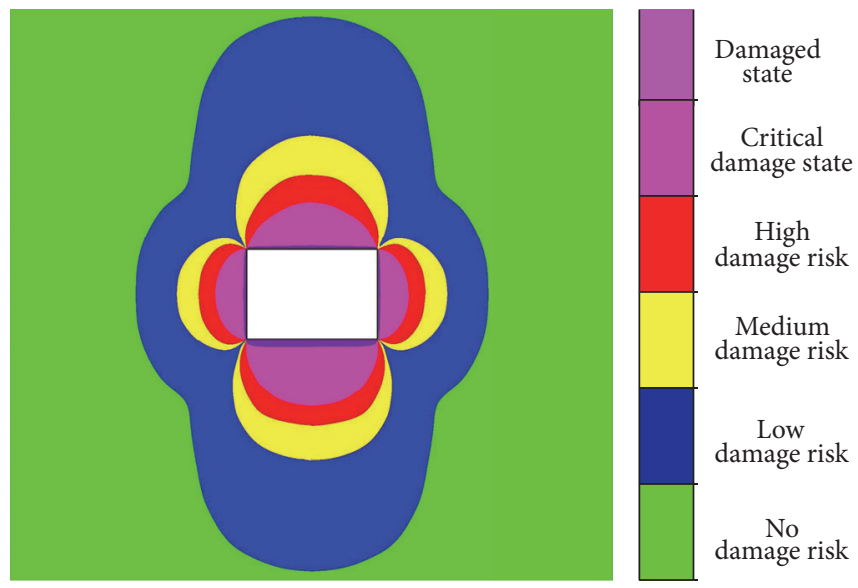

(f) Damage risk grade

FIGURE 7: Distributions of damage risk grades and conventional analysis indexes of roadway surrounding rocks under static loads.

However, the overall damage risks of surrounding rocks from high to low, which are all higher than those under static loads, are as follows: floor (51.92\%), roof (50.91\%), the sidewall near the source $(43.56 \%)$, and the sidewall remote from the source (33.87\%), and also areas of damaged zones are in a descending order as follows: roof $\left(14.75 \mathrm{~m}^{2}\right)$, floor $\left(10.78 \mathrm{~m}^{2}\right)$, the sidewall near the source $\left(7.19 \mathrm{~m}^{2}\right)$, and the sidewall remote from the source $\left(5.61 \mathrm{~m}^{2}\right)$ under the stable state after dynamic disturbances. The reason for this is that the stress wave strength of dynamic loads reduces with the 


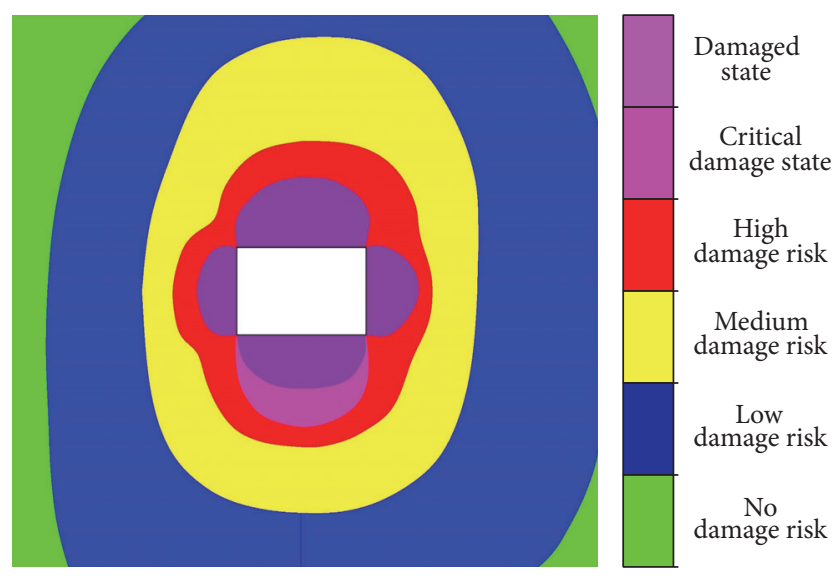

FIGURE 8: Distributions of damage risk grades under the stable state after dynamic disturbances.

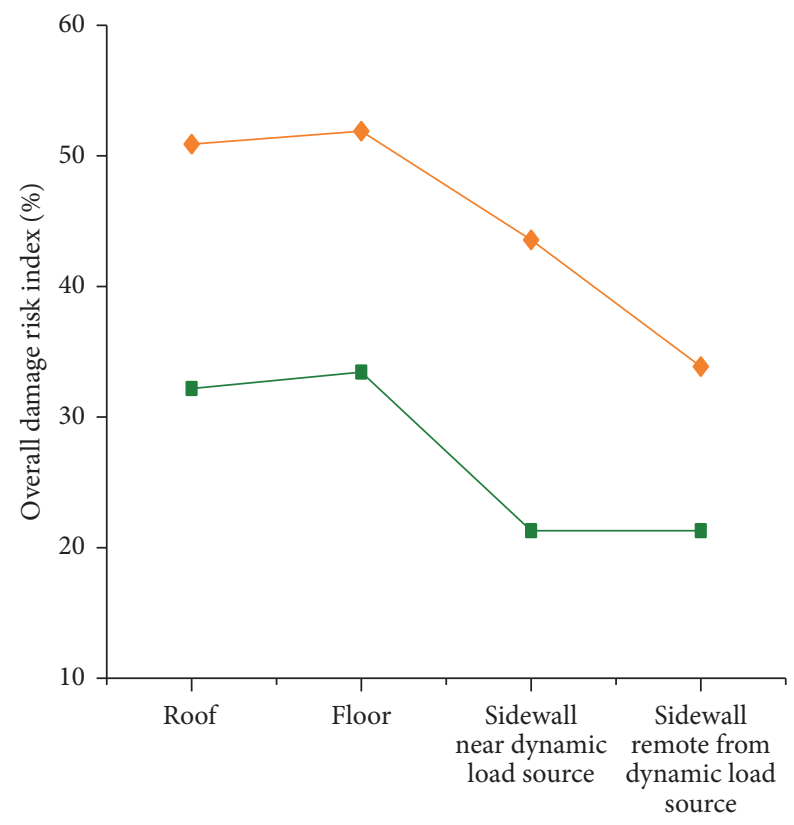

Location

$$
\rightarrow \text { Under static loads }
$$

FIGURE 9: Overall damage risk indexes of roadway surrounding rocks.

increase of spreading distance in the transmission. Besides, the transmission of dynamic loads is obstructed by the roadway space, which significantly decreases the strength of stress waves as they diffract through the roadway. Therefore, the roof and the sidewall near the source are greatly influenced by dynamic loads, while the floor and the sidewall remote from the source are slightly affected by dynamic loads. Under the superposition of static and dynamic loads, although the floor is damaged more seriously than the roof under static loads, the damage degree of the roof is heavier than that of the floor

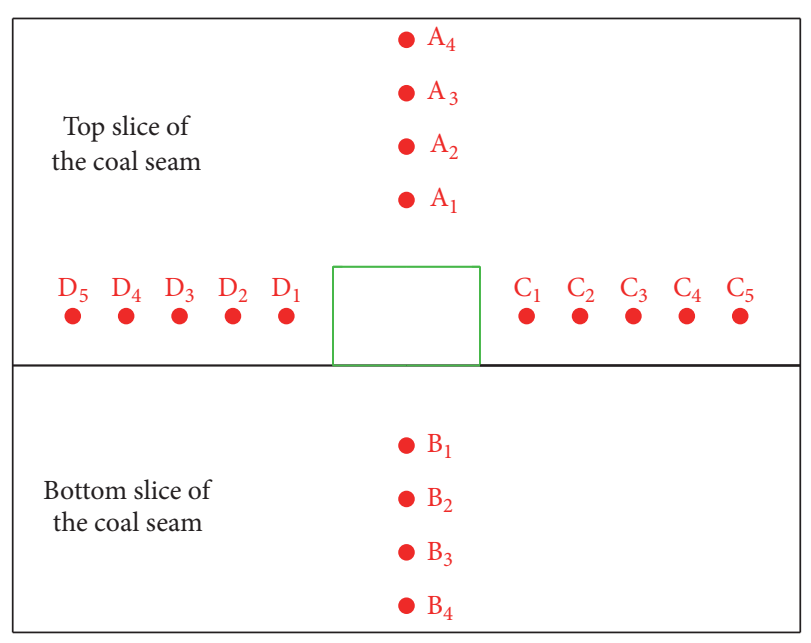

FIGURE 10: Arrangement diagram of monitoring points in roadway surrounding rocks.

under the stable state after dynamic disturbances. Likewise, the damage degrees of the two sidewalls are consistent under static loads, while the sidewall near the source is damaged more obviously than that remote from the source under the stable state after dynamic disturbances. This indicates that dynamic loads not only aggravate the damage (increasing the ranges of damaged zones) of shallow surrounding rocks, but also make the high risk areas transfer to deep surrounding rocks, which accordingly leads to increasing damage risks.

Although the roof is damaged more significantly than the sidewall near the source under the stable state after dynamic disturbances, it does not mean that the influencing degree of dynamic loads on the roof is greater than that on the sidewall near the source. Therefore, for further analyzing the influencing degrees and response characteristics in each position of surrounding rocks under dynamic loads, it is necessary to research the time-history change laws of damage risks.

\subsubsection{Time-History Responses of the Analysis Index of Damage} Risks. In order to study the change laws of the overall damage risks of surrounding rocks with time, the monitoring points closest to roadway surfaces were set in the damage risk zones near to the boundaries of critical damage zones and damage risk zones under static loads. By using the monitoring points closest to roadway surfaces as reference points, the rest of monitoring points were set within a $10 \mathrm{~m}$ range away from the roadway surfaces with an interval of $2 \mathrm{~m}$. All monitoring points, whose two-dimensional coordinates are shown in Table 4, were located at the central lines of each side of the roadway (Figure 10).

The time-history response curves of damage risk indexes of surrounding rocks are revealed in Figure 11, where the straight lines in red, yellow, and blue represent the high, medium, and low damage risks, respectively. The influence of the stress waves of dynamic loads lasts for $0.25 \mathrm{~s}$. The damage risk indexes of each monitoring point maintain stable for a certain time at the beginning, indicating that a time 


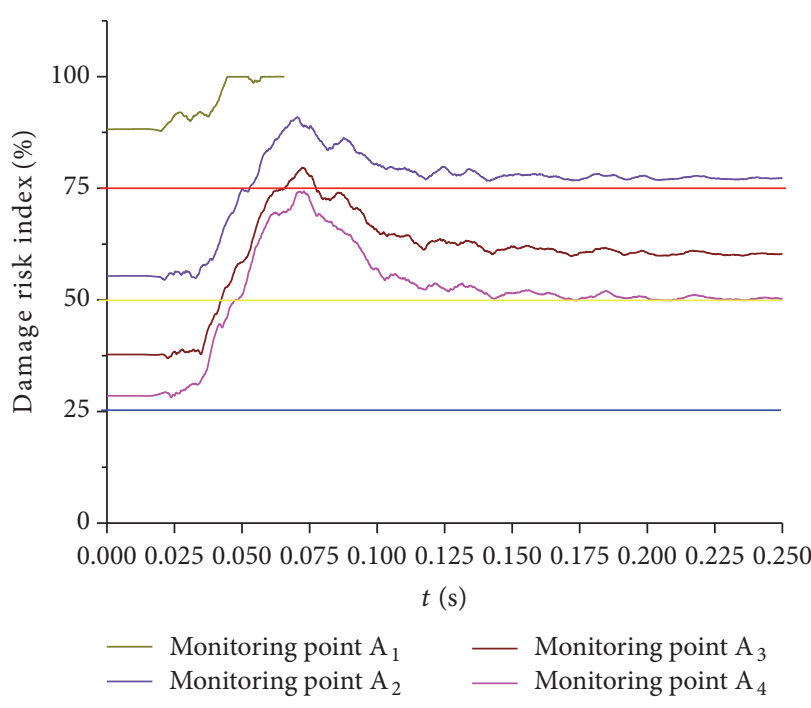

(a) Roof

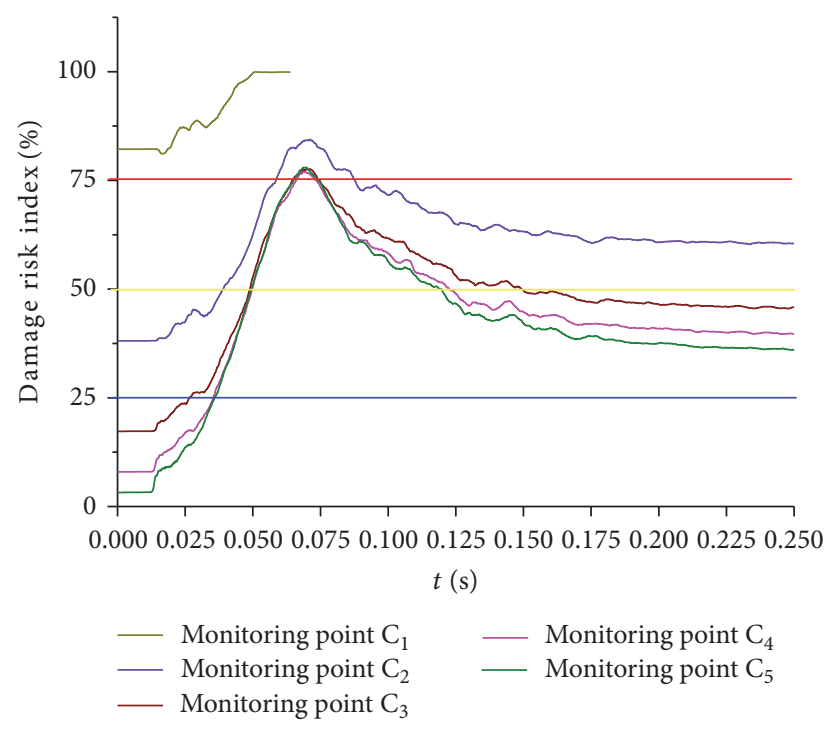

(c) Sidewall near the dynamic load source

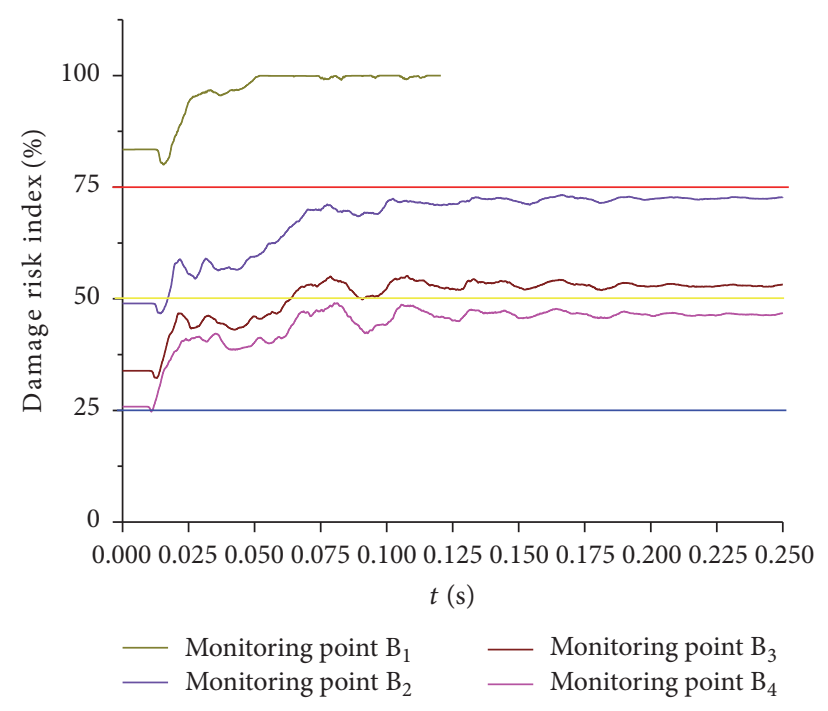

(b) Floor

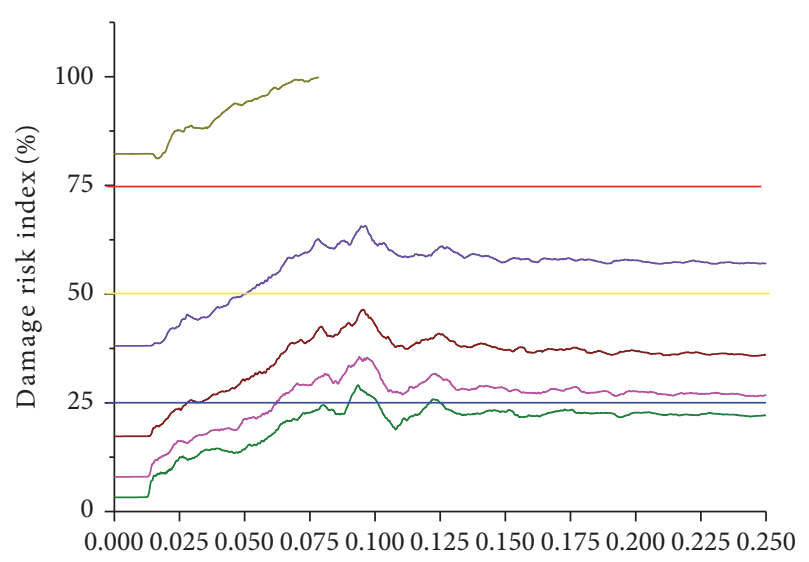

$t(\mathrm{~s})$

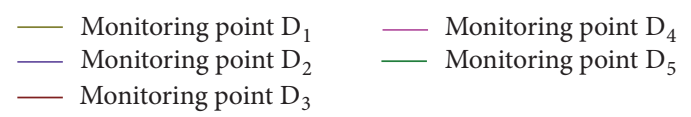

(d) Sidewall remote from the dynamic load source

FIGURE 11: Time-history response curves of damage risk indexes of roadway surrounding rocks.

TABLE 4: Two-dimensional coordinates of monitoring points.

\begin{tabular}{lccccc}
\hline Location & 1st monitoring point & 2nd monitoring point & $\begin{array}{c}\text { 3rd monitoring } \\
\text { point }\end{array}$ & $\begin{array}{c}\text { 4th monitoring } \\
\text { point }\end{array}$ & $\begin{array}{c}\text { 5th monitoring } \\
\text { point }\end{array}$ \\
\hline Roof & $\mathrm{A}_{1}(20.00,26.20)$ & $\mathrm{A}_{2}(20.00,28.20)$ & $\mathrm{A}_{3}(20.00,30.20)$ & $\mathrm{A}_{4}(20.00,32.20)$ & - \\
Floor & $\mathrm{B}_{1}(20.00,17.00)$ & $\mathrm{B}_{2}(20.00,15.00)$ & $\mathrm{B}_{3}(20.00,13.00)$ & $\mathrm{B}_{4}(20.00,11.00)$ & - \\
$\begin{array}{l}\text { Sidewall near the source } \\
\text { Sidewall remote from the }\end{array}$ & $\mathrm{C}_{1}(24.50,21.85)$ & $\mathrm{C}_{2}(26.50,21.85)$ & $\mathrm{C}_{3}(28.50,21.85)$ & $\mathrm{C}_{4}(30.50,21.85)$ & $\mathrm{C}_{5}(32.50,21.85)$ \\
source & $\mathrm{D}_{1}(15.50,21.85)$ & $\mathrm{D}_{2}(13.50,21.85)$ & $\mathrm{D}_{3}(11.50,21.85)$ & $\mathrm{D}_{4}(9.50,21.85)$ & $\mathrm{D}_{5}(7.50,21.85)$ \\
\hline
\end{tabular}

difference exists as stress waves spread from the source to roadway surrounding rocks so that the dynamic responses of surrounding rocks are delayed. The dynamic responses of monitoring points of the roof, floor and two sidewalls show the following common characteristics. Firstly, the damage risk index of the 1st monitoring point stably increases with time to $100 \%$ when damage occurs. Secondly, the timehistory response laws of damage risk indexes of the 2nd4 th/5th monitoring points are consistent, representing almost synchronously changes. 
However, the monitoring points in the roof, floor, and two sidewalls also exhibit greatly different response characteristics. The dynamic response curves of the 1st monitoring points in each position of surrounding rocks are incomplete since they have already been damaged when their damage risk indexes reach $100 \%$. This is also the reason why the 1st monitoring points are not analyzed in terms of the dynamic response. The time-history curves for the damage risk of the 2nd-4th monitoring points (namely, $\mathrm{A}_{2}-\mathrm{A}_{4}$ ) in the roof and the 2nd-5th monitoring points (namely, $\mathrm{C}_{2}-$ $\mathrm{C}_{5}$ ) in the sidewall near the source present obvious single peaks similar to the half-sine form of the source (Figures $11(\mathrm{a})$ and $11(\mathrm{c}))$. Although the 2nd-5th monitoring points (namely, $\mathrm{D}_{2}-\mathrm{D}_{5}$ ) in the sidewall remote from the source show certain single peaks, the fluctuation degree is far less than the above two positions, while the damage risks of the 2nd-4th monitoring points (namely, $\mathrm{B}_{2}-\mathrm{B}_{4}$ ) in the floor increase in stable fluctuations and finally stabilize without single peaks appearing (Figures 11(b) and 11(d)). The above analysis demonstrates that the roof and the sidewall near the source are most seriously influenced by dynamic loads, followed by the sidewall remote from the source and then the floor.

In order to quantitatively describe the influencing degrees of dynamic loads in each position of surrounding rocks, an index (dynamic influence index $\Delta W_{\mathrm{d}}$ regarding damage risks) is defined as

$$
\Delta W_{\mathrm{d}}=W(t)_{\max }-W_{0}
$$

where $W(t)_{\max }$ and $W_{0}$ represent the dynamic response peak of damage risk index and the static damage risk index at a certain monitoring point, respectively.

Due to nonexisting dynamic response peaks on the timehistory response curves of damage risk indexes in the floor, the comparison of the dynamic influence indexes regarding damage risks of each monitoring point only needs to be made in the roof and the two sidewalls, as shown in Figure 12. The influence degrees of dynamic loads are found to be highest on the sidewall near the source, followed by the roof and the sidewall remote from the source. As for the roof and the sidewall near the source, the further the monitoring points are from the roadway surfaces (closer to the source), the greater the influences of dynamic loads are. As for the sidewall remote from the source, the influence degree of dynamic loads firstly improves and then weakens with the increasing distance of monitoring points to the roadway surfaces. The reason is that the stress waves diffract thereby producing diffraction waves when passing through the roadway space. Under such condition, the superposition and disturbance of diffraction waves in different directions weaken the strength of stress waves around the roadway surfaces [32]. Therefore, the surrounding rocks around the roadway surfaces are less evidently affected by dynamic loads than those with certain distances from the roadway surfaces. Meanwhile, the strengths of diffraction waves gradually decrease with the increase of spreading distance. In summary, the influence degree of dynamic loads on the sidewall remote from the source presents the above variation characteristics.

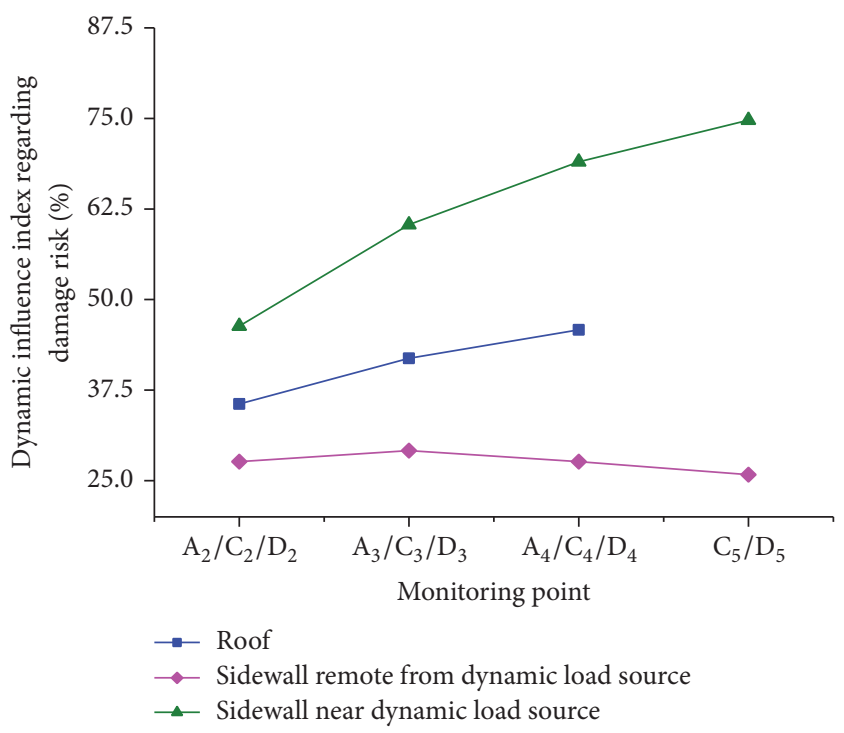

FIGURE 12: Comparison of dynamic influence indexes regarding damage risks on the roof and the two sidewalls.

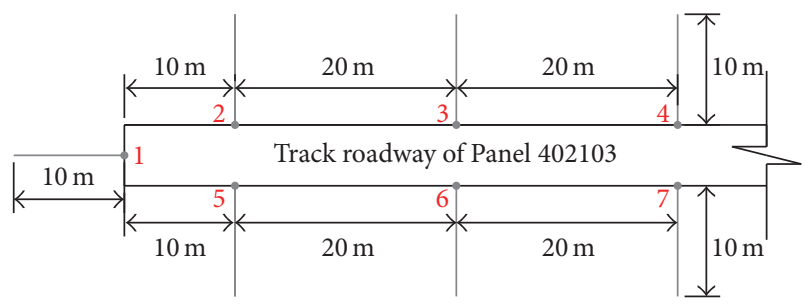

FIGURE 13: Layout plan of drilling cutting monitoring boreholes.

Based on the analysis results in Section 3.2.2 and this section, the damage degree (damage risk) of roadway surrounding rocks under dynamic loads is determined by the damage degree (damage risk) under static loads and the influence degree of dynamic loads. For example, although the influence degree of dynamic loads on the sidewall near the source is greater than that on the roof, the damage degree (damage risk) in the roof is higher than that in this sidewall under the superposition of dynamic and static loads.

\section{Case Study}

Hujiahe Coal Mine, owned by the Binchang Coal Group, is situated in the Shaanxi Province, China. The study area, Longwall Panel 402103, is the first mining face in number 402 District. A monitoring and forecasting system combining with the Microseismic Monitoring System named ARAMIS introduced from Poland and Drilling Cutting Method was adopted in order to guarantee the safe tunneling in track roadway of Panel 402103. Figure 13 shows the layout plan of drilling cutting monitoring boreholes during the tunneling in track roadway of Panel 402103. The diameter and drilling depth of each borehole are $42 \mathrm{~mm}$ and $10 \mathrm{~m}$, respectively. These boreholes are about $1.2 \mathrm{~m}$ away from the roadway floor and the direction of holes is all parallel to the coal seam. 


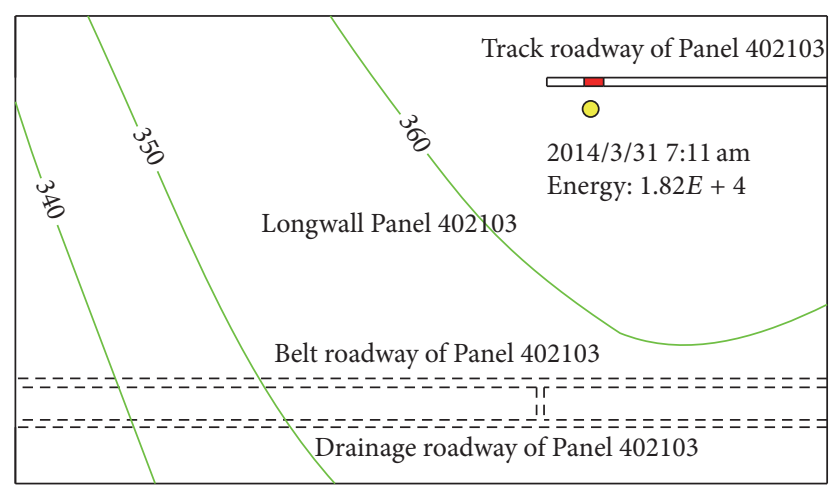

FIGURE 14: Locations of dynamic load source and rockburst occurrence in Longwall Panel 402103.

A borehole was drilled at the heading face and this hole will be monitored once every five-meter advancing while the monitoring will be carried out every day if advancing rate is lower than five meters per day. Besides, three boreholes, which need to be monitored once a day, were drilled in each sidewall of the roadway behind the heading face, and distances of these holes to the face are $10 \mathrm{~m}, 30 \mathrm{~m}$, and $50 \mathrm{~m}$, respectively. The main monitoring content is the drilling cutting quantity per meter (unit $\mathrm{kg} / \mathrm{m}$ ), which is starting from the second meter.

According to the in situ data, three rockbursts induced by dynamic loads occurred during the track roadway excavation in Longwall Panel 402103. A typical rockburst occurrence, coal burst with an energy of $1.82 \times 10^{4} \mathrm{~J}$ caused by blasting occurring at 7:11 am, March 31, 2014, is taken as an example (Figure 14). The oblique incident mine earthquake source showed a horizontal distance of $13.8 \mathrm{~m}$ and a vertical distance of $7.3 \mathrm{~m}$ to the closer sidewall and the roof of the track roadway, respectively. In addition, the rockburst position (red area in Figure 14) was 23-35 m away from the heading face of track roadway.

The damage risks of rockburst can qualitatively be reflected by the drilling cutting quantity, namely, the more the drilling cutting quantity, the higher the damage risk. Therefore, $3^{\#}$ and $6^{\#}$ boreholes (Figure 13), which are closest to the location of rockburst occurrence, were taken as the research object, and two comparable boreholes were drilled adjacent to $3^{\#}$ and $6^{\#}$ boreholes with distance of $1 \mathrm{~m}$ after rockburst occurrence. Figure 15 shows comparisons of the drilling cutting quantity in $3^{\#}$ and $6^{\#}$ boreholes before and after rockburst occurrence. It can be seen that drilling cutting quantities in both $3^{\#}$ and $6^{\#}$ boreholes have the similar changing law before the rockburst, namely, the deeper the drilling depth, the fewer the drilling cutting quantity, which indicates that the damage risk of rockburst is gradually decreased from the roadway surface to deep surrounding rocks. However, the drilling cutting quantities in both $3^{\#}$ and $6^{\#}$ boreholes are characterized by increasing at first and then decreasing after the rockburst. Firstly, $3^{\#}$ and $6^{\#}$ boreholes are located on the sidewall remote from the source and the sidewall near the source, respectively. Besides, the peak value position of drilling cutting quantity in $6^{\#}$ borehole is

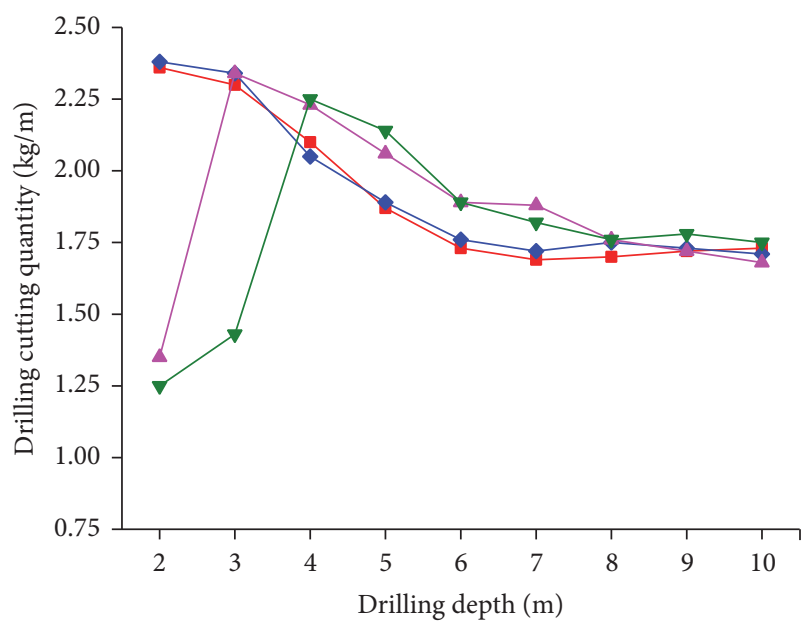

$\rightarrow 3^{\#}$ borehole (before rockburst) $-3^{\#}$ borehole (after rockburst) $\longrightarrow 6^{\#}$ borehole (before rockburst) $\rightarrow 6^{\#}$ borehole (after rockburst)

FIGURE 15: Comparisons of drilling cutting quantities before and after rockburst.

further away from the roadway surface than that of drilling cutting quantity in $3^{\#}$ borehole, which indicates that damage of surrounding rocks near the roadway surface results in the decline of corresponding damage risks with high damage risks being transferred to deep surrounding rocks, and the damage degree of the sidewall near the source is far greater than that of the sidewall remote from source. It is obvious that the distribution characteristics of damage risks reflected by the drilling cutting quantity are basically consistent with numerical simulation results obtained from the analysis in Sections 3.2.1 and 3.2.2.

Figure 16(a) demonstrates in situ damage situations in the track roadway of Panel 402103. Obvious cracks and 0.31$0.36 \mathrm{~m}$ of floor heave were found in the floor. Six anchor bolts in the roof were loose and the roof subsided by $0.45-0.58 \mathrm{~m}$. Moreover, three anchor bolts in the sidewall near the source were loose with convergence ranging from $0.23 \mathrm{~m}$ to $0.28 \mathrm{~m}$. However, the anchor bolts were not loose in the sidewall remote from the source where the convergence ranges from $0.18 \mathrm{~m}$ to $0.21 \mathrm{~m}$.

Figure 16(b) shows the sketch map of damaged regions in roadway surrounding rocks. In this figure, anchor bolts and cables without anchorage failure are marked in green, while anchor bolts with anchorage failure are marked in red. In addition, damaged regions of roadway surrounding rocks expressed in Section 3.2.2 are marked in purple. Obviously, the range of damaged region in the roof is larger than or very close to anchorage regions of six bolts with anchorage failure in the middle part of the roof, and the range of damaged zones in the sidewall near the source extremely approaches the anchorage regions of three bolts with anchorage failure in the middle part of this sidewall, while that in the sidewall remote from the source does not affect the bolt anchorage end. All these lead to "loose behavior" (namely, the anchorage failure with these bolts losing their anchor foundations under dynamic loads) of anchor bolts in the roof and sidewall near 


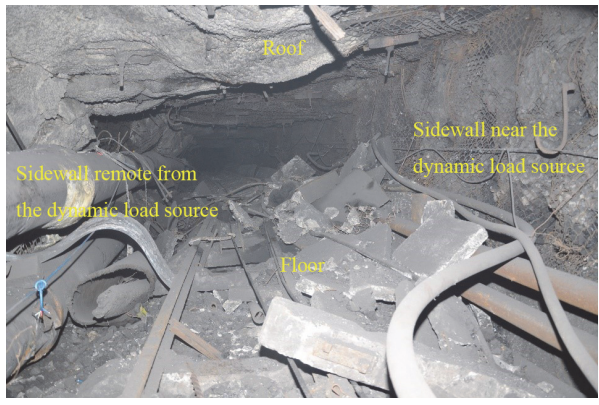

(a) In situ damage situations

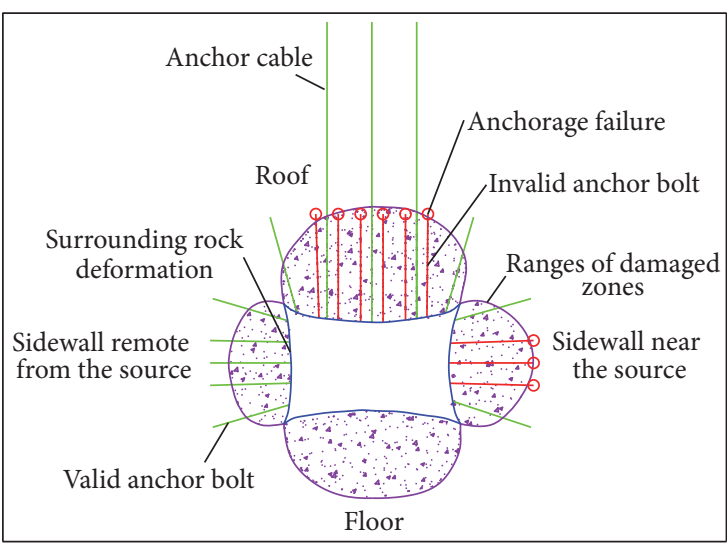

(b) Sketch map of damage regions

FIgURE 16: Rockburst damage in the track roadway of Longwall Panel 402103.

the source, while bolts in the sidewall remote from the source are not loose. Furthermore, damage degrees of surrounding rocks can to some extent be reflected by their deformations. The rockburst is found to induce decreasing deformation degrees in the roof, floor, the sidewall near the source, and the sidewall remote from the source, which coincides with the ranking results of damage degrees of surrounding rocks obtained from the analysis in Section 3.2.2. In summary, the accuracy and scientificity of the numerical simulation results are verified due to the fact that all above analysis results are in good agreement with the in situ damage situations of rockburst.

\section{Conclusions}

Based on Mohr-Coulomb strength criterion, a damage risk index to evaluate damage risks of roadway surrounding rocks was established, and four damage risk grades (namely, high, medium, low, and no damage risks) were classified. The damage risk index of roadway surrounding rocks under dynamic loading is a function changing with time.

All conventional analysis indexes only reflect the stress distribution characteristics of coal-rocks from a certain aspect in two-dimension space, while all stress components can be considered by the damage risk index, with the evaluation criteria quantified, which can comprehensively reveal the stress states and damage of coal-rock masses.

The overall damage risks and degrees of roadway surrounding rocks reflect the results of superposition of dynamic and static loads, which are found to be in a descending order in the floor, roof, and two sidewalls merely under static loads, while the sidewall near the source is most obviously affected by the oblique incident dynamic load, followed by the roof, the sidewall remote from the source, and the floor successively. Taken together, there are decreasing damage degrees shown in the roof, floor, sidewall near the source, and sidewall remote from the source under the stable state after dynamic disturbances. The dynamic load not only aggregates the damage of shallow surrounding rocks, but also increases the damage risks of deep parts.

Distribution characteristics of damage risks and damage degrees in roadway surrounding rocks reflected by the drilling cutting quantity, the anchorage failure of bolts and deformations of surrounding rocks in situ are basically consistent with the numerical analysis results, which verifies the accuracy and scientificity of analysis methods in this paper.

\section{Competing Interests}

The authors declare that there is no conflict of interests regarding the publication of this paper.

\section{Acknowledgments}

Financial support for this work provided by the State Key Research Development Program of China (Grant no. 2016YFC0801403), the Key Project of National Natural Science Foundation of China (Grant no. 51634001), the Key Research Development Program of Jiangsu Provence (no. BE2015040), and the Priority Academic Program Development of Jiangsu Higher Education Institutions (no. SZBF20116-B35) is gratefully acknowledged.

\section{References}

[1] L.-M. Dou and X.-Q. He, Theory and Technology of Rock Burst Prevention, China University of Mining and Technology Press, Xuzhou, China, 2001.

[2] W. D. Ortlepp and T. R. Stacey, "Rockburst mechanisms in tunnels and shafts," Tunnelling and Underground Space Technology, vol. 9, no. 1, pp. 59-65, 1994.

[3] F. Kirzhner and G. Rosenhouse, "Numerical analysis of tunnel dynamic response to earth motions," Tunnelling and Underground Space Technology, vol. 15, no. 3, pp. 249-258, 2000. 
[4] K. Holub and V. Petroš, "Some parameters of rockbursts derived from underground seismological measurements," Tectonophysics, vol. 456, no. 1-2, pp. 67-73, 2008.

[5] J. Kabiesz and J. Makówka, "Selected elements of rock burst state assessment in case studies from the Silesian hard coal mines," Mining Science and Technology, vol. 19, no. 5, pp. 660-667, 2009.

[6] R. Patyñska and J. Kabiesz, "Scale of seismic and rock burst hazard in the Silesian companies in Poland," Mining Science and Technology, vol. 19, no. 5, pp. 604-608, 2009.

[7] L. Dou, T. Chen, S. Gong, H. He, and S. Zhang, "Rockburst hazard determination by using computed tomography technology in deep workface," Safety Science, vol. 50, no. 4, pp. 736-740, 2012.

[8] D. Song, E. Wang, N. Li, M. Jin, and S. Xue, "Rock burst prevention based on dissipative structure theory," International Journal of Mining Science and Technology, vol. 22, no. 2, pp. 159$163,2012$.

[9] S. Dehghan, K. Shahriar, P. Maarefvand, and K. Goshtasbi, “3-D modeling of rock burst in pillar No. 19 of Fetr6 chromite mine," International Journal of Mining Science and Technology, vol. 23, no. 2, pp. 231-236, 2013.

[10] J. He and L. Dou, "Gradient principle of horizontal stress inducing rock burst in coal mine," Journal of Central South University, vol. 19, no. 10, pp. 2926-2932, 2012.

[11] L. Wang, Z. Lu, and Q. Gao, "A numerical study of rock burst development and strain energy release," International Journal of Mining Science and Technology, vol. 22, no. 5, pp. 675-680, 2012.

[12] P. Horyl and R. Šnupárek, "Reinforcing measures of steel roadway support in rockburst prone areas," Archives of Mining Sciences, vol. 57, no. 1, pp. 193-208, 2012.

[13] M.-S. Gao, Y.-C. Zhao, Y.-Y. Wen, Z.-C. Cheng, and X.-C. Quan, "Stress and energy criterion of the roadway destruction subjected to disturbance type rock burst and its practice," Meitan Xuebao/Journal of the China Coal Society, vol. 41, no. 4, pp. 808-814, 2016.

[14] J. Ning, J. Wang, Y. Tan, and X. Shi, "Dissipation of impact stress waves within the artificial blasting damage zone in the surrounding rocks of deep roadway," Shock and Vibration, vol. 2016, Article ID 4629254, 13 pages, 2016.

[15] Z.-Y. Wang, L.-M. Dou, and G.-F. Wang, "Failure mechanism of anchored bolt supporting structure of circular roadway under dynamic load," Chinese Journal of Geotechnical Engineering, vol. 37, no. 10, pp. 1901-1909, 2015.

[16] C.-P. Lu, G.-J. Liu, H.-Y. Wang, and J.-H. Xue, "Numerical investigation of rockburst effect of shock wave on underground roadway," Shock and Vibration, vol. 2015, Article ID 867582, 10 pages, 2015.

[17] Z.-Y. Yang, J.-C. Gu, B.-S. Yang, A.-M. Chen, and J.-M. Xu, "Numerical analysis of reinforcement effects and response to dynamic loads characteristics of rock bolts," Yantu Lixue/Rock and Soil Mechanics, vol. 30, no. 9, pp. 2805-2809, 2009.

[18] S. S. Peng, Coal Mine Ground Control, China University of Mining and Technology Press, Xuzhou, China, 3rd edition, 2013.

[19] M.-F. Cai, M.-C. He, and D.-Y. Liu, Rock Mechanics and Engineering, The Science Publishing Company, Beijing, China, 2012.

[20] L.-M. Dou and X.-Q. He, "Technique of classification forecasting rock burst in coal mines," Journal of China University of Mining \& Technology, vol. 36, no. 6, pp. 717-722, 2007.
[21] L.-M. Dou, Z.-L. Mu, Z.-L. Li, A.-Y. Cao, and S.-Y. Gong, "Research progress of monitoring, forecasting, and prevention of rockburst in underground coal mining in China," International Journal of Coal Science and Technology, vol. 1, no. 3, pp. 278-288, 2014.

[22] W. Cai, L.-M. Dou, Z.-L. Li, J. Liu, S.-Y. Gong, and J. $\mathrm{He}$, "Microseismic multidimensional information identification and spatio-temporal forecasting of rock burst: a case study of Yima Yuejin coal mine, Henan, China," Chinese Journal of Geophysics, vol. 57, no. 8, pp. 2687-2700, 2014.

[23] Z.-L. Li, L.-M. Dou, G.-F. Wang, W. Cai, J. He, and Y.-L. Ding, "Risk evaluation of rock burst through theory of static and dynamic stresses superposition," Journal of Central South University, vol. 22, no. 2, pp. 676-683, 2015.

[24] Itasca Consulting Group, FLAC Fast Lagrangian Analysis of Continua User's Guide, Itasca Consulting Group, Minneapolis, Minn, USA, 2005.

[25] G. Zhu, L. Dou, Y. Liu et al., "Dynamic behavior of fault slip induced by stress waves," Shock and Vibration, vol. 2016, Article ID 4386836, 13 pages, 2016.

[26] G.-X. Chen, L.-M. Dou, M.-S. Gao, and Z.-L. Mu, "Numerical simulation of dynamic vibration affecting rock burst in mining gateway caused by tremor," Journal of Mining \& Safety Engineering, vol. 26, no. 2, pp. 153-157, 2009.

[27] H. Qin, Research on Mechanism of Roadway Surrounding Rock Instablity and Rockburst, China University of Mining and Technology, Xuzhou, China, 2008.

[28] J. He, Research of Mining Dynamic Loading Effect and Its Induced Rock Burst in Coal Mine, China University of Mining and Technology, Xuzhou, China, 2013.

[29] S.-Y. Gong, L.-M. Dou, X.-J. Xu, J. He, C.-P. Lu, and H. He, "Experimental study on the correlation between stress and Pwave velocity for burst tendency coal-rock samples," Caikuang yu Anquan Gongcheng Xuebao/Journal of Mining and Safety Engineering, vol. 29, no. 1, pp. 67-71, 2012.

[30] B. H. G. Brady and E. T. Brown, Rock Mechanics for Underground Mining, Science Press, Beijing, China, 2011.

[31] ABAQUS, ABAQUS Online Documentation: Ver 6.4-1, ABAQUS, Inc, 2003.

[32] G.-Y. Wang, Technic Study on Enhancing the Explosion Resisting Capacity of Underground Opening Reinforced by Rockbolts, University of Science and Technology of China, Hefei, China, 2009. 


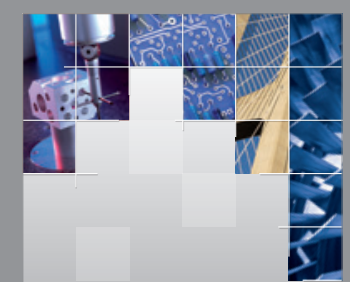

\section{Enfincering}
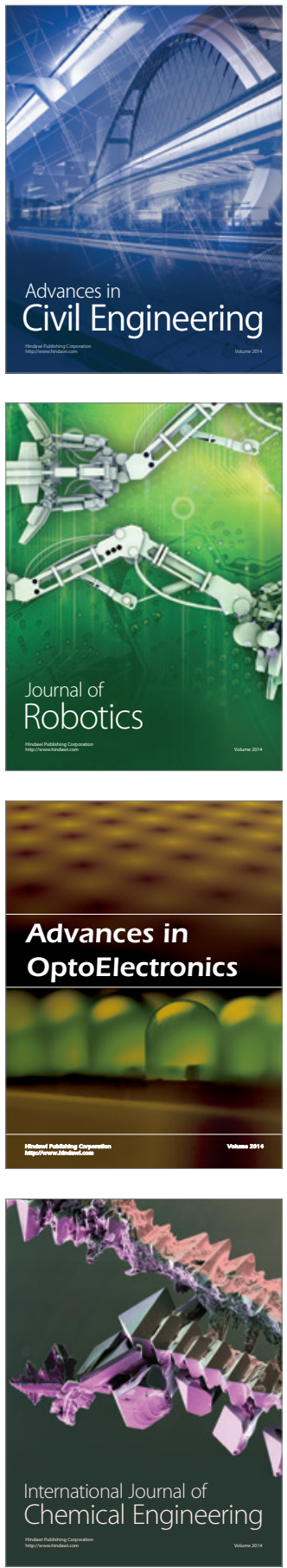

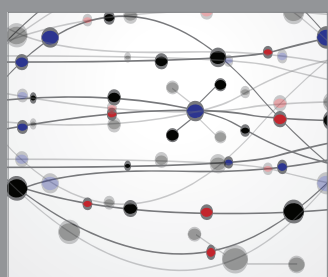

The Scientific World Journal

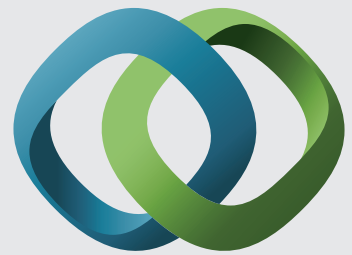

\section{Hindawi}

Submit your manuscripts at

https://www.hindawi.com
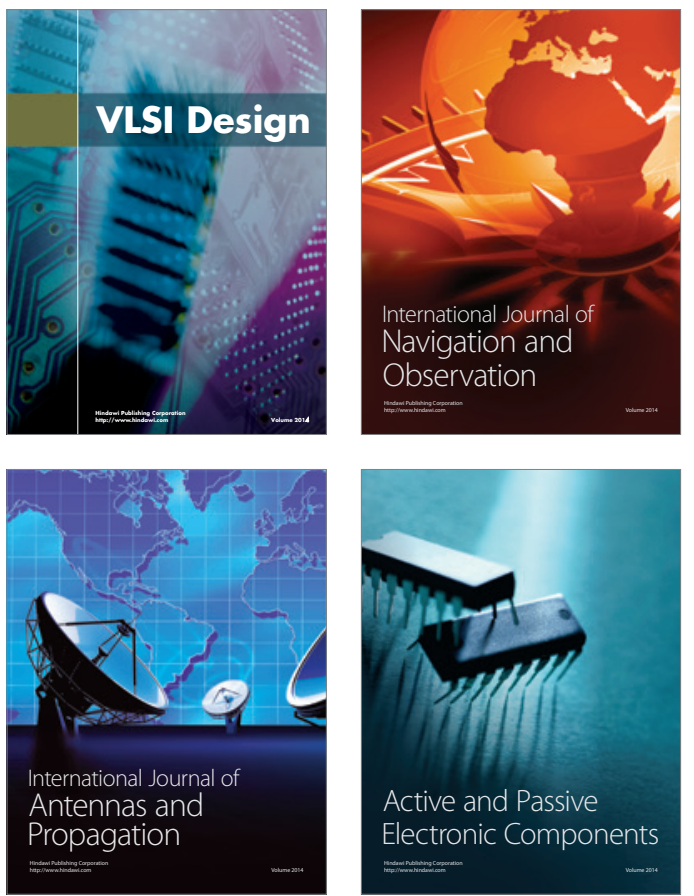
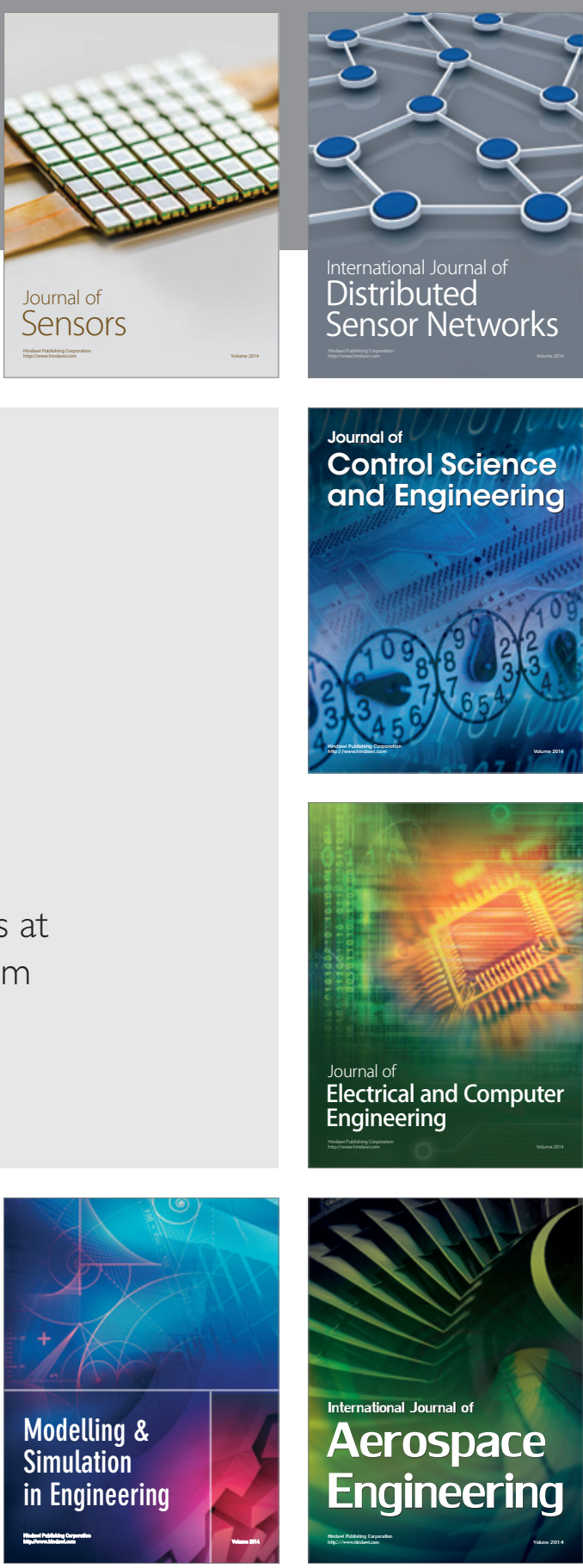

International Journal of

Distributed

Sensor Networks

$-$

Joumal of

Control Science

and Engineering
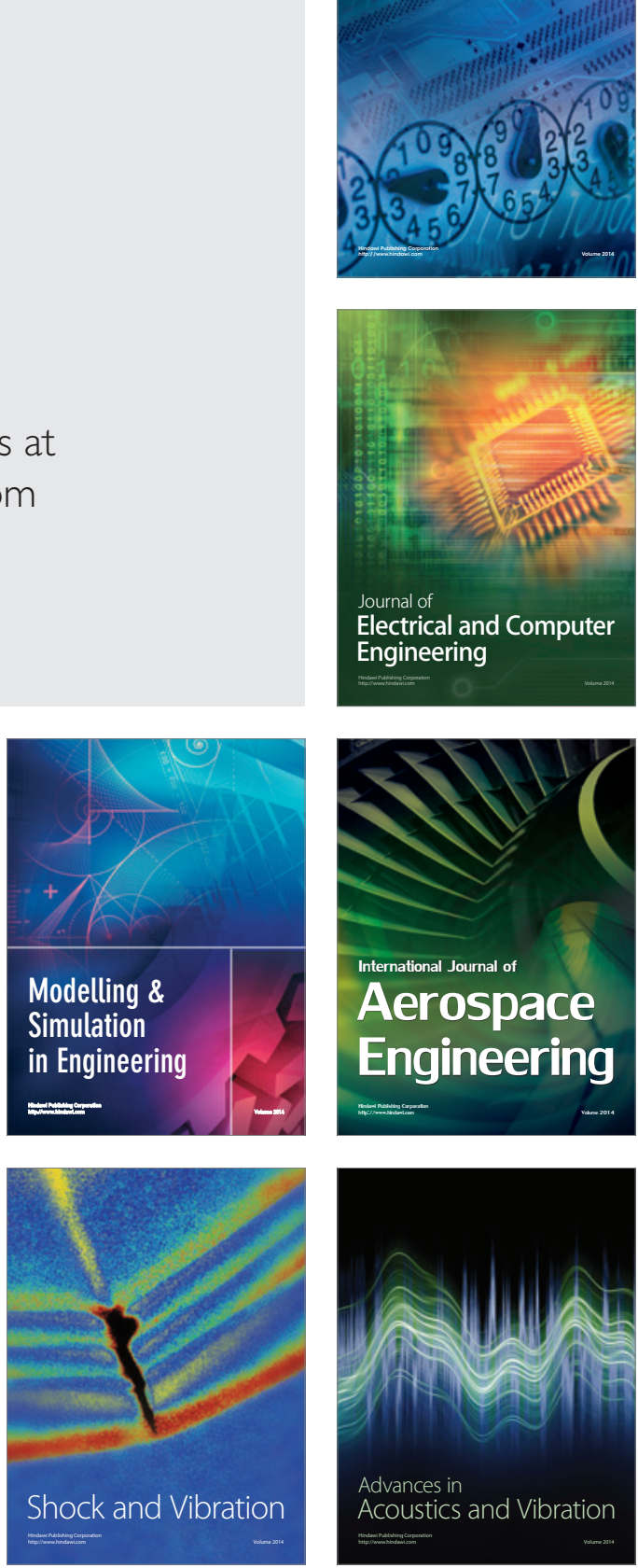